\title{
Introduction to the Proceedings of WoRIE'21
}

\author{
Carlos RODRÍGUEZ-DOMÍNGUEZ ${ }^{\mathrm{a}}$, Aditya SANTOKHEE ${ }^{\mathrm{b}}$, \\ Miguel J. HORNOS ${ }^{\mathrm{a}, 1}$ and Juan C. AUGUSTO ${ }^{\mathrm{c}}$ \\ ${ }^{a}$ Software Engineering Department, University of Granada, Granada, Spain \\ ${ }^{\mathrm{b}}$ Department of Computing, Middlesex University Mauritius, Mauritius \\ ${ }^{\mathrm{c}}$ Department of Computer Science, Middlesex University, London, United Kingdom
}

This section of the proceedings is a compilation of the accepted contributions to be presented at the 10th International Workshop on the Reliability of Intelligent Environments (WoRIE 2021), which should have been held within the 17th International Conference on Intelligent Environments (IE 2021) in Dubai, UAE, on June 21-24, 2021. However, due to the on-going pandemic caused by the COVID-19 outbreak, the whole conference is being held completely online for a second consecutive year, as happened with IE'20, planned to be held in Madrid (Spain). We believe that it is necessary for greater effort and collaboration between researchers and practitioners to provide a more holistic and unified methodology to develop higher quality IEs. Thus, this event aims to serve as a forum whereby researchers, academics and professionals engaged in the development of Intelligent Environments (IEs) can discuss about how to make them more reliable, safer, and securer, as well as increasing user confidence in them.

We are grateful to Dr. Stefano Chessa for accepting our invitation to give the keynote speech of this edition. His talk will focus on reliability of an e-health prototype operating within the context of IEs. The selected contributions cover wide ranging topic areas representing a well-balanced distribution of theoretical and practical efforts: security issues of cloud-based IoT system, discussion on functionalities offered by recent versions of a computational tool to construct and evaluate mathematical models which estimate system behaviours, findings of the integration between a fuzzy controller and a connected digital home, development of multi-purpose conversational systems using a modular architecture, and an assessment of uncertainty in whole building simulation models. With all this, we hope to have a successful and fruitful workshop, where all the audience actively participate and discuss on the topics addressed. We also expect that readers enjoy the selected papers included in these proceedings.

On a final note, we wish to express our sincere thanks to the authors of the submitted papers for their very interesting and high-quality contributions; WoRIE'21 Program Committee members, for their excellent work and invaluable support during the review process; and IE'21 Workshops Chairs, for their help and support. All of them have made possible to successfully organize the present edition of this workshop, which is being consolidated year after year.

1 Corresponding author, Software Engineering Department, University of Granada, E.T.S. de Ingenierías Informática y de Telecomunicación, 18071 Granada, Spain; E-mail: mhornos@ugr.es. 